\title{
DEGENERATION AND REGENERATION OF CORNEAL NERVES*
}

\author{
BY \\ BROR REXED AND URSULA REXED \\ From the Nobel Institute for Neurophysiology, Karolinska Institutet, Stockholm
}

CerTain authors, such as Haab (1899), Kraupa (1924), and Walsh (1947), have suggested that there might be an inter-relation between certain diseases of the cornea and the condition of the corneal nerves. The diseases mentioned are recurrent erosion of the cornea, superficial punctate keratitis, herpetic keratitis, and certain forms of degeneration of the corneal epithelium. Neuroparalytic keratitis and herpes zoster ophthalmicus are known to be dependent on injury to or disease of the ophthalmic division of the trigeminal nerve.

Before attempting to study diseased conditions of the corneal nerves, an exact knowledge of the normal corneal innervation and of the reactions of the nerves to simple traumatic injury is necessary. Results obtained from experimental work on animals should to a certain extent be applicable to processes in the human corneal nerves.

Such investigations have been made by Leoz Ortin (1915), who studied the corneal sensitivity after partial and total keratotomy. He obtained a corneal reflex 60 days after the operation, and found good nerve regeneration in histologic sections taken 8 months after the operation. Jent (1945) performed circular incisions of the corneal stroma down to Descemet's membrane and then examined the nerves in vital staining. He also studied the corneal sensitivity in these cases with von Frey hairs. He found that the nerves were less stainable after 24-48 hours, after 5 days they could not be stained at all ; after 28 days, small sprouting neurites could be stained in the old pathways.

\section{Material AND Methods}

These investigations have been performed on 41 eyes from 26 rabbits enucleated from 3 days to $6 \frac{1}{2}$ months after operation. Six of the rabbits were adults, the rest being young animals about 6 months old. An incision, covering from $90-360^{\circ}$ of the circumference of the cornea, was made through the stroma and down to Descemet's membrane. The sensitivity of the cornea was tested from 1-3 days after the operation

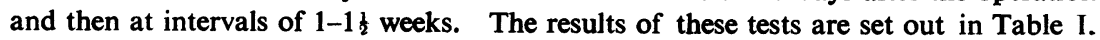

* Received for publication September 2, 1950. 
TABI.E I

\begin{tabular}{|c|c|c|}
\hline \multirow{2}{*}{$\begin{array}{l}\text { Time after } \\
\text { Operation }\end{array}$} & \multicolumn{2}{|c|}{ Sensitive Area } \\
\hline & $\begin{array}{l}\text { Immediately } \\
\text { inside scar } \\
\text { (weeks) }\end{array}$ & $\begin{array}{l}\text { Over whole } \\
\text { cornea } \\
\text { (weeks) }\end{array}$ \\
\hline $\begin{array}{r}\text { 3-5 days } \\
7 \text { days } \\
7 \text { days } \\
11 \text { days } \\
3 \text { weeks } \\
3 \text { weeks } \\
3 \text { weeks } \\
1 \text { month } \\
1 \text { month } \\
1 \text { month } \\
1 \text { month } \\
1 \frac{1}{2} \text { months } \\
2 \frac{3}{4} \text { months } \\
5 \text { months } \\
\text { * } 5 \frac{1}{2} \text { months } \\
56 \frac{3}{4} \text { months } \\
\text { *6 months } \\
\text { * } 6 \frac{1}{2} \text { months }\end{array}$ & $\begin{array}{c}\bar{z} \\
\overline{1} \\
2 \\
>10 \text { days } \\
\overline{-} \\
\overline{3} \\
4 \\
3 \\
>2 \\
4 \\
3 \\
3 \\
6 \\
5 \\
6 \\
7\end{array}$ & $\begin{array}{c}- \\
\overline{-} \\
\overline{3} \\
\overline{-} \\
\frac{4}{\overline{4}} \\
\overline{4} \\
\overline{4} \\
>4 \\
7 \text { to } 8 \\
7 \\
7 \text { to } 8 \\
8\end{array}$ \\
\hline
\end{tabular}

TABLE II

\begin{tabular}{c|c}
\hline $\begin{array}{c}\text { Time after } \\
\text { Operation }\end{array}$ & $\begin{array}{c}\text { No. of } \\
\text { Preparations }\end{array}$ \\
\hline 3 days & 2 \\
5 days & 2 \\
7 days & 4 \\
8 days & 1 \\
11 days & 1 \\
12 days & 1 \\
14 days & 3 \\
3 weeks & 4 \\
24 days & 2 \\
28 days & 1 \\
29 days & 1 \\
30 days & 1 \\
36 days & 1 \\
41 days & 1 \\
$1 \frac{1}{2}$ months & 1 \\
$2 \frac{3}{4}$ months & 1 \\
5 months & 3 \\
$5 \frac{1}{2}$ months & 1 \\
$5 \frac{3}{4}$ months & 1 \\
6 months & 1 \\
$6 \frac{1}{2}$ months & \\
\hline
\end{tabular}

The testing of the corneal sensitivity was performed with von Frey hairs held at right angles to the cornea, under illumination by a slit lamp so that the scar could be seen easily. Acccording to our experience, the grading of the sensitivity of the cornea in experimental animals, as performed by certain authors, must be considered unreliable. Even a simple marking out of sensitive and insensitive areas must be far from accurate. The animals are very capricious and often inhibit a positive reflex when scared.

After enucleation of the eye, the cornea with limbus was cut out. Three radial cuts were made in order to flatten out the preparation. This was then fixed in a 10 per cent. solution of neutral formaldehyde to which had been added 1.1 per cent. $\mathrm{NaCl}$. On fixing in formaldehyde only the corneal epithelium often peeled off ; we found the addition of $\mathrm{NaCl}$ lessened this tendency. The concentration of $\mathrm{NaCl}$ was chosen on account of the findings of von Bahr $(1941,1948)$ that cornea placed in solutions of $\mathrm{NaCl}$ of this concentration did not swell or shrink. The preparations also seemed to take the silver stain better when fixed in this solution. We fixed for at least three days. Some preparations were left in fixing solution for longer times, up to 2 months, without becoming less stainable. The preparations are listed in Table II.

Before sectioning, the cornea was spread out flat on the freezing microtome with the epithelium upwards and was frozen down as flat as possible. It was then cut in sections $\mathbf{1 0 0}$ microns thick parallel to the surface of the spread-out cornea. Except for the first sections, which were often incomplete, this gave circular preparations covering the whole of the cornea in which individual nerve fibres could be traced over wide distances. The sections were silver-impregnated according to the method of Gros-Schultze. 


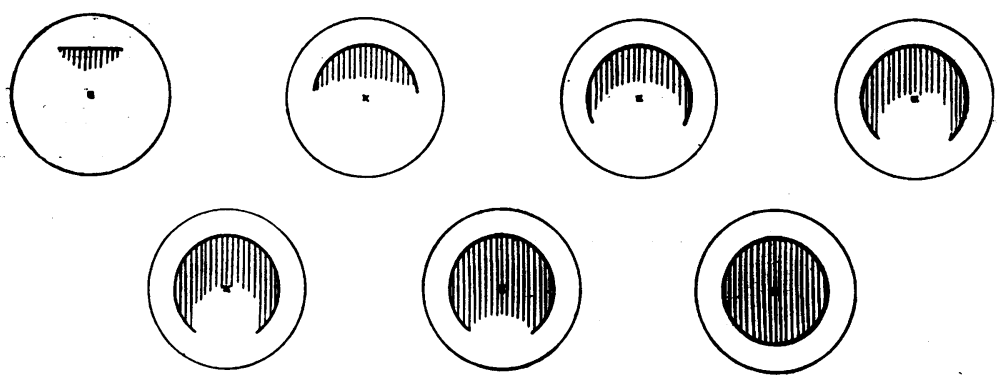

FiG.1.-Insensitive area of cornea after incisions of different lengths. Striated area $=$ insensitive.

\section{Results}

The denervated insensitive area on the cornea was always found to be smaller than the sector corresponding to the peripheral arcuate cut (Fig. 1). The central parts of the cornea did not generally become insensitive when the incision covered less than $300^{\circ}$ of the circumference. The insensitive area was thus sickle shaped with the concave part directed towards the centre (Fig. 1). This is explained by the dichotomic division of the nerves after they have crossed the limbus. Tower (1940) studied the nerve impulses in isolated corneal nerve fibres, and found that one such fibre can branch over nearly a quarter of the cornea.

A corneal reflex could be elicited from just inside the scar after 2 to 4 weeks in young animals and after 5 to 7 weeks in adults. Once the regenerated nerves had crossed the scar they appeared to spread quickly (Fig. 2, A). Thus the whole of the cornea was found to be sensitive after 3 to 5 weeks in younger animals and after 7 to 8 weeks in adults. The passage through the scar appears to give the greatest resistance to the regenerating nerve fibres and thus to

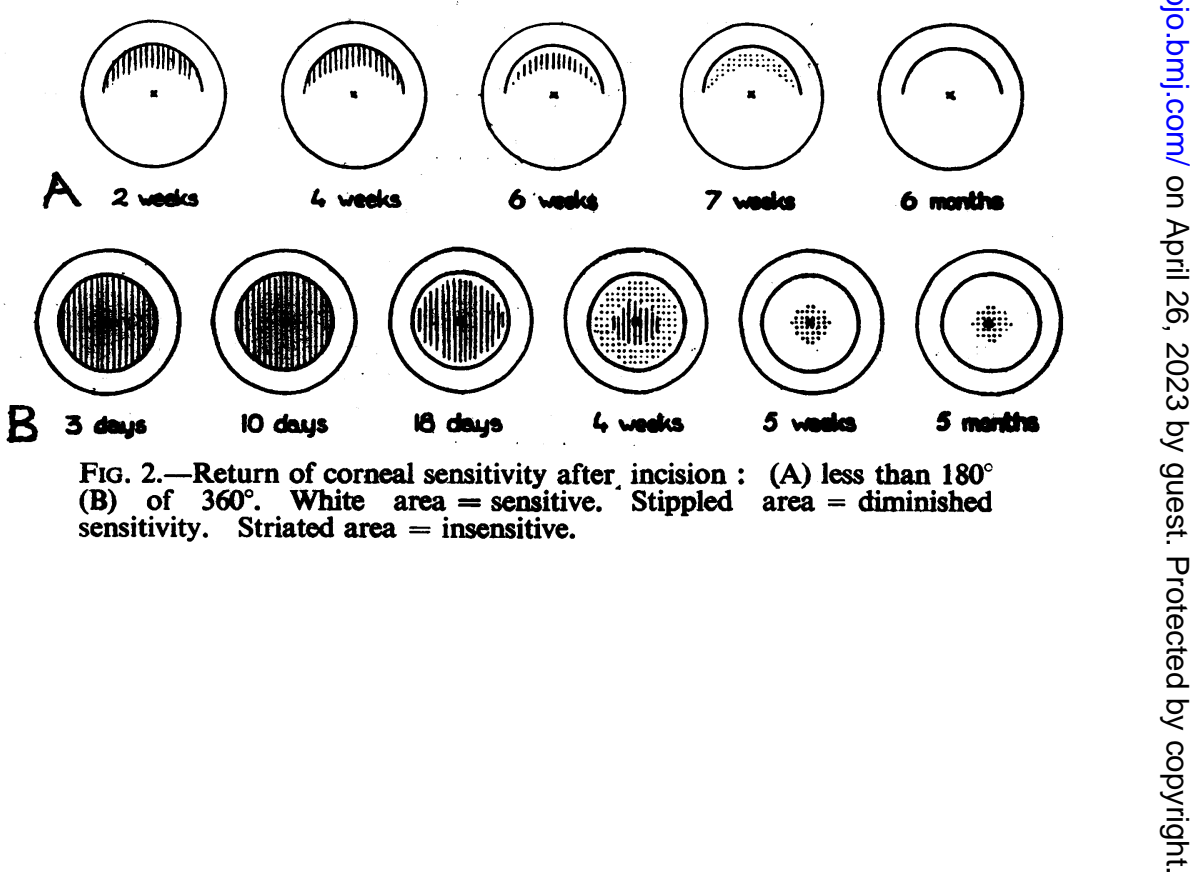


take the longest time. Once the scar is crossed the new neurites grow more quickly.

In two cases the incision was made round the whole of the circumference of the cornea so that all nerve fibres were severed. In these two cases we found that even after 3 months in the one, and 5 months in the other case, the centre of the cornea was less sensitive than the surrounding parts (Fig. 2, B).

It has been suggested (Weddell and others, 1941) that a small denervated skin area can be re-innervated by the sprouting of new neurites from adjacent uninjured ones. Edds (1949) worked with partially denervated muscles, and stated that paralytic motor units became re-innervated in partially denervated muscles by sprouts from remaining uninjured nerve fibres.

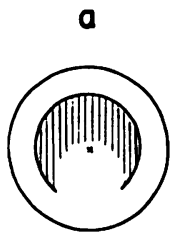

19.5
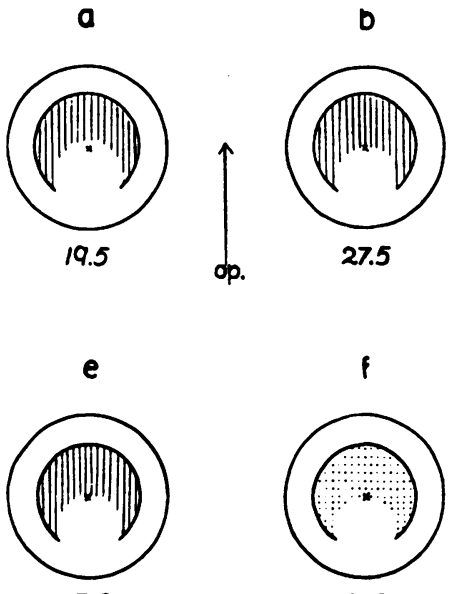

17.0

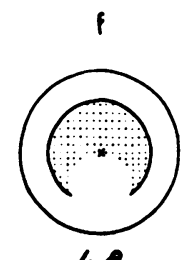

4.8
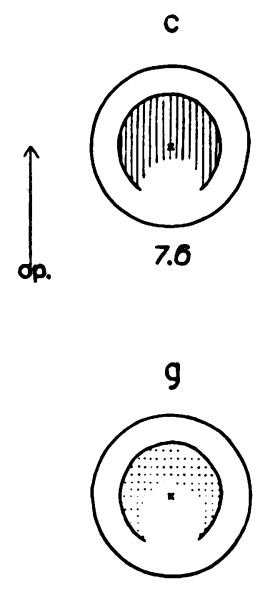

5.10
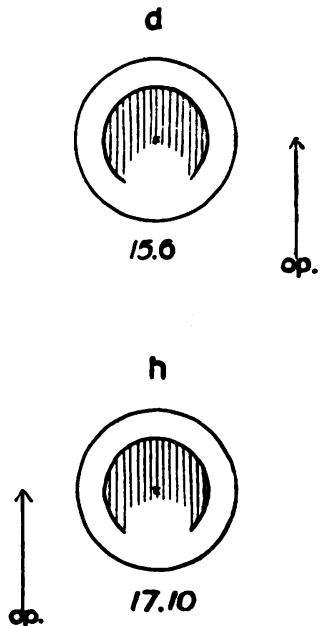

FIG. 3.-Corneal sensitivity after repeated incisions in the same scar. Arrows signify re-operation. In $(f)$ and $(g)$ the area inside the scar has had time to regain sensitivity. White area $=$ sensitive. Stippled area $=$ diminished sensitivity. Striated area $=$ insensitive.

In order to decide whether a denervated part of the cornea could be re-innervated by neurites growing in from adjacent areas, in four cases the incision scar was re-opened several times at intervals of 1 to 4 weeks, all the nerves being severed each time. After each operation the sensitivity of the cornea was tested, and the insensitive area was of the same size and form (Fig. 3). This experiment shows that the cornea was re-innervated by neurites that had grown through the scar and not from adjacent uninjured nerves.

\section{Histological ObSERVATIONS}

Degeneration of Corneal Nerves.-The method of cutting used seems to have bruised the nerves very little. The severed end of the nerve can often be seen in the preparation 
with a sharply defined edge. The strictly localized trauma perhaps explains the fact that so few neurites degenerate in a retrograde direction. Only a few of the nerves show signs of such degeneration and then only for $0.5 \mathrm{~mm}$. backwards. Most of the fibres are seen to send out thin filaments towards the scar from the severed end.

Inside the scar one finds a rapid degeneration of the severed neurites. After 3 days there are many degenerated fibres, after 5 days only a few intact ones are to be seen, and after 7 days all the fibres seem to have degenerated. The resorbtion of the fragments is rapid, and after the 7 th day no degeneration products remain. Thin fibres possibly disintegrate somewhat later than coarse ones but the difference is not great. The few myelinated fibres that have been cut, degenerate in the usual way with ovoid formation of the myelin.

The severed neurites inside the scar degenerate along their whole course. We have not seen any remaining peripheral parts of the fibres or any undegenerated network of fibres as described by Reiser (1937).

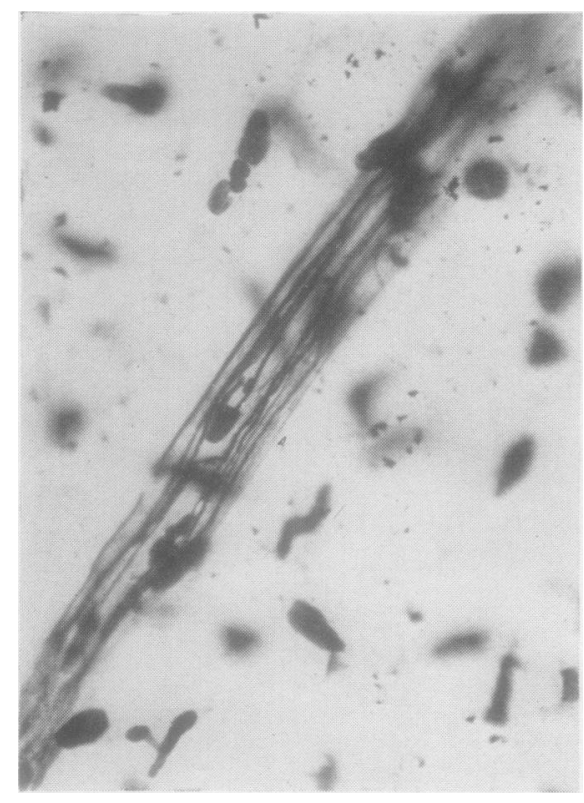

FIG. $4(a)$. - Normal nerve with several neurites in Schwann sheaths. (High magnification).

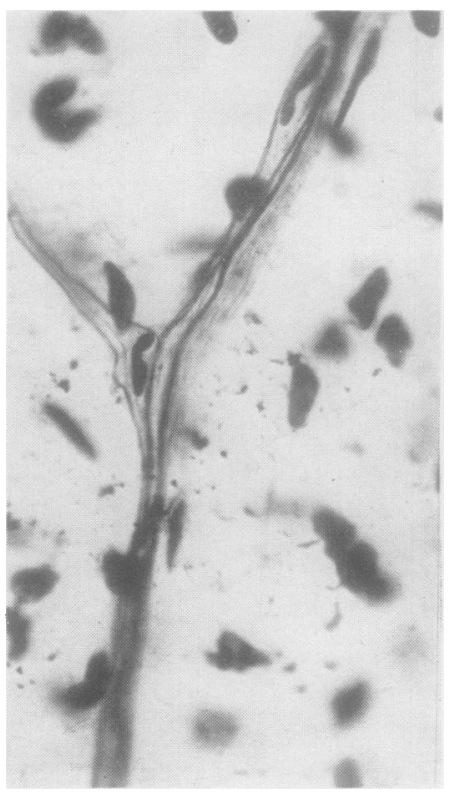

Fig. 4 (b). - Dividing nerve trunk. (High magnification).

Schwann Cells.-We found that the reaction of the Schwann cells after severance of corneal nerves differs from that seen in other nerves. The severed nerve end can easily be localized even several weeks after the operation. It is then seen outside the scar as a sharply defined, clear-cut edge, from which a number of new neurites are growing out. The Schwann cells can easily be seen and studied, and no reaction from them was seen in any of the preparations. No mitoses were observed. The Schwann cells do not proliferate from the severed end of the nerve to take part in the bridging of the scar for the new neurites.

The lack of all reaction from the Schwann cells at the cut ends of the corneal nerves both inside and outside the scar explains why such cells never are seen in the scar tissue 
in the cornea. In nerves other than corneal, the Schwann cells play an active part in crossing the gap between the severed ends, and form a bridge for the proliferating neurites (Rexed, 1942). In the cornea, however, the gap is filled only by stroma cells, and the neurites receive no assistance from Schwann cells in bridging the gap between the severed nerve ends.

In the nerve stump inside the scar there is no reaction of the Schwann cells as in the peripheral stump of other severed nerves. No mitoses have been seen and there appears to be no increase in the number of nuclei in the bands of Schwann cells inside the scar.

The reactions of the Schwann cells which are seen in other parts of the body are entirely absent in the central and peripheral ends of severed corneal nerves.

The corneal nerves inside the scar are not of quite the same appearance after degeneration as before. With the histological technique used here it is very difficult to see any boundaries between the Schwann cells of the different neurites in an intact corneal nerve. Several authors consider the Schwann cells to be made up of a syncytium (Boeke, 1926 ; Nageotte and Guyon, 1926), regarding them as continuous and forming a large cylinder common to all the neurites of the nerve. A few days after section of the nerves we found that they began to take on a striated appearance (Fig. 5), although all the neurites had degenerated. In a few places, especially where the nerve trunk divides, one can see that the apparently homogeneous nerve sheath consists of a bundle of empty Schwann cells. Even when most of the nerves have regenerated one can find separate Schwann sheaths which have not become re-innervated.

Re-innervation.-The severed ends of the nerves on the outside of the scar show regeneration reactions after 3 days. Single neurites then send out small filamentous processes which grow from the neurite towards the scar or parallel to it. On the 5th day many of the nerves have sent out neurites towards the scar and on the 7th day one finds a profuse proliferation. Nearly all the severed neurites ultimately send out new ones (Fig. 6) which grow out either from the cut edge or from the last few millimeters nearest the cut.

The new neurites do not usually grow through the scar directly, but often follow it for a distance before turning and penetrating it (Fig. 7). Thus whole bundles of new neurites run in a circular direction, close to the outside, and just inside, the scar. In tissue culture, growing neurites often follow preformed structures in the substrate, i.e., they grow stereotactically (Weiss, 1934). The corneal cells show a tendency to arrange themselves end to end along the circular scar, and the axons follow the cells in the same direction.

Once they have arrived there, the new neurites soon cross the scar. Five days after section single neurites grow into the scar, and by the 7th day several will have penetrated it. After 12 to 21 days an increasing network of new fibres may be seen inside the scar in the denervated cornea (Fig. 8).

Since there is no proliferation whatsoever of the Schwann cells, the neurites penetrate the scar without any Schwann sheath. Sometimes a neurite may be seen growing alcng an elongated cell which might be considered to be a sheath cell, but it often leaves these cells and grows out on its own. This manner of growth can be explained as stereotaxis, the neurite seeking a mechanical support. Where such relations between neurites and cells are not seen one must assume that the neurite is supported by intercellular structures, which do not stain with the technique used.

Both inside and outside the scar a large number of fibres grow in bundles in a circular direction. After the neurite has grown for a short stretch along the scar, it 
turns and grows in towards the centre of the cornea. In this zone one often finds a new proliferation of neurites. Those which have crossed the scar divide repeatedly

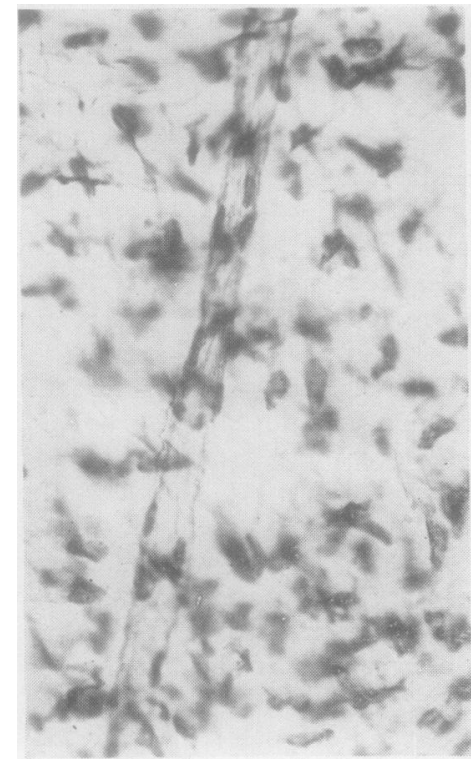

Fig. 5.-Denervated nerve trunk 21 days after severance. The empty Schwann sheaths are slightly striated. (High magnification).

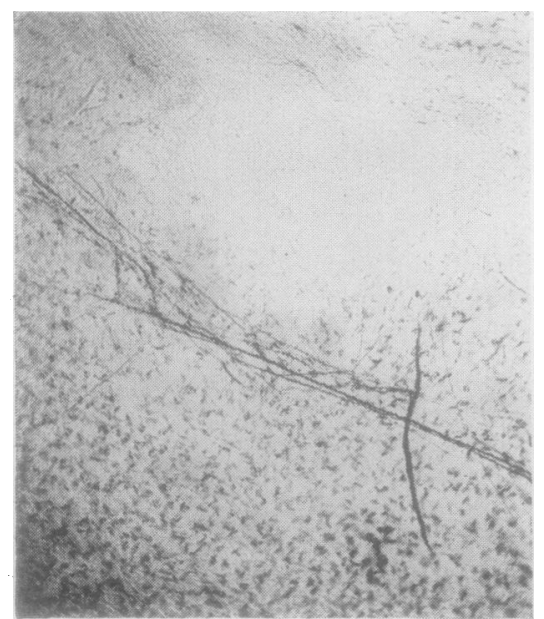

FIG. 7.-New neurites growing circularly outside the scar which can be seen in the top right-hand corner of the picture. 43 days after severance. (Low magnification).

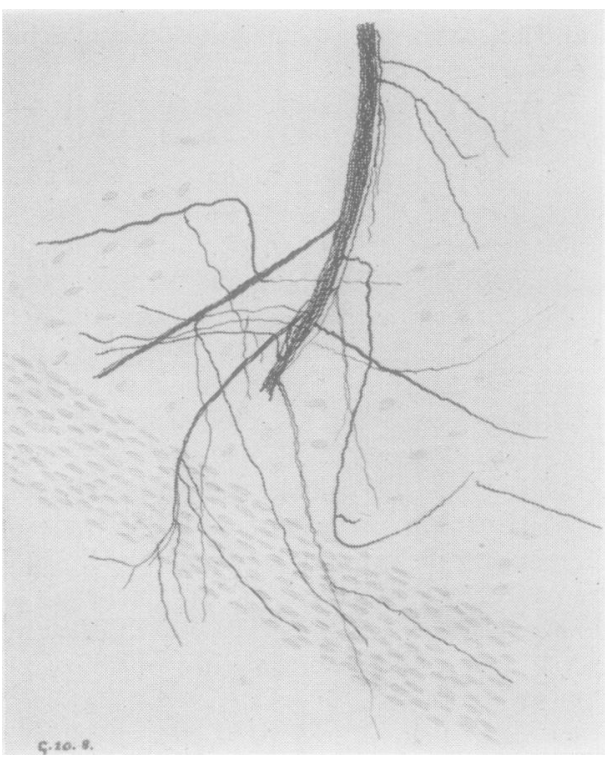

FIG. 6.-Nerve trunk outside the scar 21 days after severance, showing sprouting of numerous new neurites. The scar is downwards in the picture. (Low magnification).

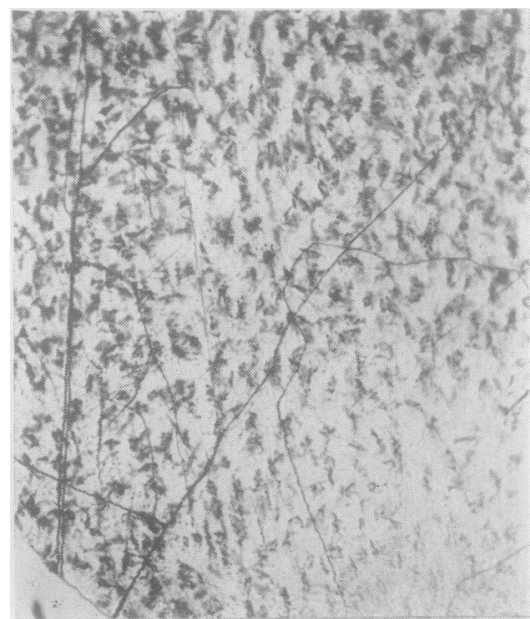

FIG. 8.-New, naked neurites dividing repeatedly inside the scar. 43 days after severance. (Medium magnification). 
and give rise to a large number of new branches, so that the number of neurites inside the scar is greatly increased.

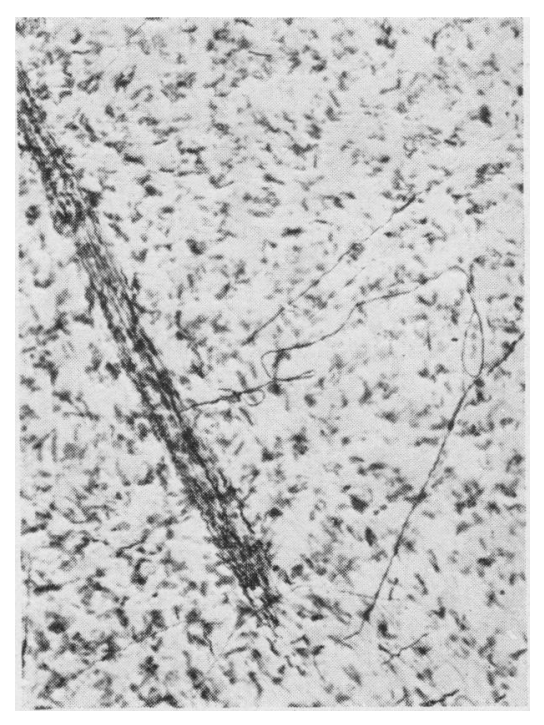

Fig. 9.- Naked neurites in the denervated area. 21 days after severance. (Low magnification).

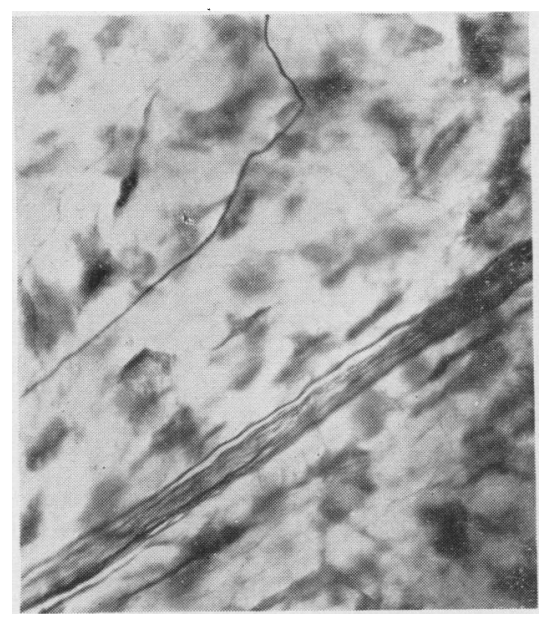

FIG. 11.-Partly re-innervated Schwann sheath with naked neurites beside it. 43 days after severance. (High magnification).

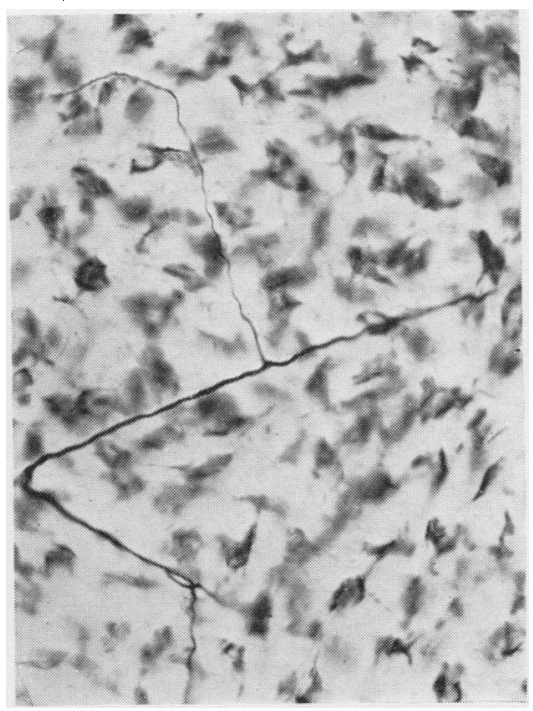

FIG. 10. - Naked neurite in the denervated area. 43; days after severance. (High magnification).

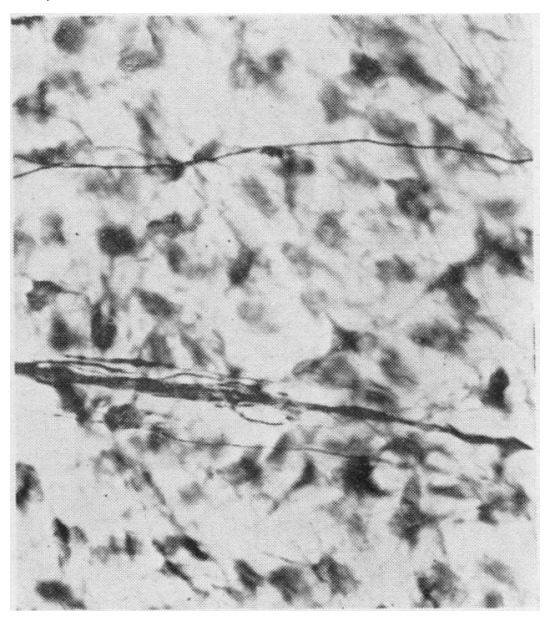

Fig. 12.-Empty Schwann sheath with naked neurites beside it. 43 days after severance. (High magnification). 
When the naked neurites leave the scar and grow into the denervated cornea, they arrive in a zone where a number of empty Schwann sheaths remain after the degeneration of the severed nerve fibres. Some neurites immediately locate the empty sheaths, grow into them through their severed ends, and continue their course inside the sheath. Other neurites grow naked towards the centre of the cornea without coming into contact with any empty sheaths (Figs 9 and 10). It seems to depend mainly on chance whether the new neurite finds an empty sheath; sometimes the new neurites grow past the cut end of an empty sheath, and elsewhere bunches of naked neurites grow forwards parallel to a partly re-innervated nerve trunk (Figs 11 and 12). No sign was observed of a stronger chemotaxis from the cut nerve on the growing neurite, as suggested by Forssman (1898).

In preparations from 12 to 14 days after the section even large nerves may be found that are not re-innervated and consist only of empty sheaths, and many of those which have become re-innervated contain only a few neurites. After 20 to 30 days most of the nerves are re-innervated and it is difficult to find empty nerve trunks. After more than 30 days no completely empty nerves are to be seen, though some small side branches may be empty. and few of the Schwann sheaths probably never become re-innervated.

In most of the preparations the naked neurites are more abundant in the peripheral and deeper parts of the cornea. Perhaps the neurites can only grow for a short distance without the support of Schwann sheaths : they manage to grow through the scar, whether because of less compact tissue or because of some positive attraction, but after this conditions seem less favourable to further growth. On account of the branching of the nerves towards the centre and surface, more empty Schwann sheaths are seen in these parts of the newly denervated cornea, which perhaps makes it easier for the neurites to find sheaths into which to grow. Whether these circumstances are important or whether other factors intervene is hard to say. However, one only finds naked neurites in the deeper and more peripheral parts of the cornea near to the scar ; here naked neurites have been seen up to $7 \frac{1}{2}$ months after operation. This shows that neurites can regenerate and grow forwards for a certain distance without the support of a Schwann sheath.

The maturation of the regenerating neurites is a slow process. At first they are all very thin ; and even 20 days after section, one finds a difference in calibre between the different neurites in the re-innervated nerves. After 30 to 40 days the variation in calibre is greater and after two months the regenerated neurites have as great a range as that of the uninjured nerves.

A sign of full regeneration is the growing in of the neurites into the subepithelial divisions of the nerves. After 20 days one can find new neurites close under the epithelial layer in the vicinity of the scar. After 26 days these subepithelial fibres are found in all parts of the denervated cornea and the older the preparation the more numerous the fibres. Because their structure is very delicate even in the normal cornea, and is therefore difficult to see in the preparations, it is hard to name any exact time for the regeneration of subepithelial nerve fibres.

The finest divisions of the nerves lying in the corneal epithelium are very difficult to study. The staining methods which have given very good results for larger fibres and above all for the Schwann sheaths, have not been completely successful for the fine intra-epithelial fibres even in the normal uninjured cornea. Therefore it has not been possible to draw definite conclusions regarding intra-epithelial nerve regeneration. In some of our older preparations however, free intra-epithelial nerve branchings of 
the same type as those seen in the normal cornea appeared, and we therefore consider that even these parts of the nerves may be regenerated. We did not see any special end-formations in any of our preparations.

\section{Discussion}

A comparison between de- and regeneration processes in ordinary peripheral nerves and in corneal nerves is of great interest. Ramon y Cajal (1928) and Boeke (1935) have reviewed the literature on these processes in peripheral nerves. The process of disintegration and resorbtion of the nerve fibres in the cornea is complete in a few days, taking much less time than in a peripheral nerve where remains of the disintegrating nerves are still to be seen after several weeks. Probably the absence of myelin sheaths in the cornea causes this difference, for in the degeneration of a peripheral nerve one finds that the myelin sheaths are the last to disappear. The axis cylinder, having a high water content, is probably more rapidly resorbed.

The absence in the cornea of every sign of reaction from the Schwann cells is the greatest difference between the process of de- and regeneration in the corneal nerves and in other peripheral nerves. Usually the proliferation of the Schwann cells bridges the gap and leads the regenerating neurites in the right direction. In all other peripheral nerves the neurites invariably grow out into the mass of proliferated Schwann sheaths, the so-called Bungners bands. Bethe (1903) considers that the Schwann cells form the new neurites, and Boeke (1935), considers them indispensable for the regeneration and growth of new neurites. The proliferation of Schwann cells is, however, an independent reaction which has an identical course even in the absence of axons (Rexed, 1942).

The experiments described here clearly demonstrate that new neurites can grow out without the support or stimulus of Schwann cells and that the axons can survive without Schwann sheaths. Since the classical experiments of Harrison in tissue cultures it has been known that naked axons can grow and proliferate in vitro. We have now been able to demonstrate that they even can grow naked in the organism in vivo, a fact that could not be ascertained in other parts of the organism on account of the simultaneous proliferation of the Schwann sheaths.

Why the Schwann cells do not proliferate in the cornea is difficult to say. Perhaps it has to do with the peculiar chemical composition of the corneal stroma. The intercellular substance is rich in mucopolysaccharides which Balazs and Holmgren (1949) have shown to have a highly inhibitive action on the proliferation of fibroblasts in tissue culture. Possibly the high concentration of these substances can inhibit the growth of Schwann cells. However, there is a 
lively proliferation of corneal cells in the scar which then ought to be inhibited in the same way. Another possible explanation is that Schwann cells do not proliferate in non-myelinated nerves (Joseph. 1948).

All other processes in the regeneration of corneal nerves take place in the same way as in other peripheral nerves.

\section{SUMMARY}

The de- and regeneration of the corneal nerves has been studied in rabbits. In 41 eyes the corneal substance was cut through down to Descemet's membrane so that the nerves were completely severed. The resulting processes in the nerves were followed. Nervous function was tested and histologic preparations were made at intervals from 3 days to $7 \frac{1}{2}$ months after operation.

The size and form of the denervated area was mapped out. By means of repeated operations it was possible to demonstrate that the re-innervation took place from the severed nerves and not from intact nerves. Good correlation was found between histologically observed re-innervation and return of sensitivity. The area immediately inside the scar regained sensitivity after 2 to 4 weeks in young animals and 5 to 7 weeks in adults. The whole of the cornea regained its sensitivity after 3 to 5 weeks in young animals and 7 to 8 weeks in adults.

The severed end of the nerve outside the scar showed little degeneration. Inside the scar the peripheral fibres degenerated after 3 days, and on the 7th day all the neurites had degenerated and the degeneration products were completely resorbed.

Schwann cells did not proliferate and did not grow out into the gap, from either the central or the peripheral cut end of the nerve. There was no proliferation of Schwann cells in the degenerated nerves.

Three days after section new neurites started to grow out from the cut nerve outside the scar. On the 7th day the growth of new neurites was abundant, and after 2 to 3 weeks there were many neurites close outside the scar. In the denervated parts of the cornea the fibres grew towards the centre, partly in the old Schwann sheaths, and partly naked without any sheath. In the more central parts of the cornea most of the neurites grew in sheaths. No.empty nerve trunks were found later than 30 days after section. After 26 days subepithelial fibres were seen in the denervated parts in all cases. The method used did not allow good staining of intraepithelial fibres. 


\section{REFERENCES}

vON BAHR, G. (1941). Acta Ophthalm., Kbh., 19, 125.

(1948). Nord. Med., 40, 2109.

Balazs, A., and Holmgren, H. (1949). Proc. Soc. exp. Biol., N. Y., 72, 142.

Bethe, A." (1903). "Allgemeine Anatomie und Physiologie des Nerven-systems" . Thieme, Leipzig.

Boeke, J. (1926). Z. mikr.-anat. Forsch., 4, 448.

(1935). “ Handbuch der Neurologie ", ed. Bumke, O., and Foerster, O., vol. 1, p. 995 . Berlin.

Edds, MaC. V., JR. (1949). Anat. Rec., 103, 534.

ForSSMAN, J. (1898). Beitr. path. Anat., 24, 56.

HAAB, O. (1899). Z. Augenheilk., 2, 235.

JENT, M. (1945). Helv. physiol. pharmacol. Acta, 3, 65.

JoSePH, J. (1948). J. Anat., Lond., 82, 146.

LeOZ ORTIN, G. (1915). Arch. Oftal. hisp.-amer., 15, 225.

KraUPA, E. (1924). Klin. Mbl. Augenheilk., 73, 229.

Nageotte, J., and Guyon, L. (1926). C. R. Ass. Anat., 21, 430.

RAMON Y CAJAL, S. (1928). " Degeneration and Regeneration of the Nervous System". Oxford Univ. Press, London.

ReISER, K. A. (1937). Arch. Augenheilk., 110, 253.

REXED, B. (1942). Z. mikr.-anat. Forsch., 51, 177.

Tower, S. S. (1940). J. Neurophysiol., 3, 486.

WALSH, F. B. (1947). "Clinical Neuro-Ophthalmology". Williams and Wilkins Co., Baltimore.

Weddell, G., Guttmann, L., and Gutmann, E. (1941). J. Neurol. Psychiat., 4, 206.

WeISS, P. (1934). J. exp. Zool., 68, 393. 